\title{
The Role of 3D Ultrasound and 3D Power Doppler Imaging in the Diagnosis and Evaluation of Ovarian Cancer: New Perspectives
}

\author{
MT Redondo, I Orensanz, FJ Salazar, S Iniesta, B Bueno, T Perez-Medina, JM Bajo \\ HU Santa Cristina, Madrid, Spain \\ Correspondence: Teresa Redondo Martín. Servicio de Ginecología, HU Santa Cristina \\ c/Maestro Vives, 2. 28009. Madrid, Spain \\ E-mail: tere_redondo@hotmail.com
}

\section{BACKGROUND}

Ovarian cancer is in frequency the third cancer of female genital tract, after those of uterus and cervix. However, its mortality is greater, and this is basically due to the difficulty in its early diagnosis, because it does not usually show symptoms until advanced stages and risk factors to develop it are unknown.

A 3000 new cases of ovarian cancer are diagnosed a year, and practically $80 \%$ of women are diagnosed in advance stages (III or IV), with a resultant overall five-year survival rate of approximately $20 \%{ }^{1}$

The current diagnostic orientation of ovarian cancer is essential, not only for the repercussion the moment of the diagnosis has in the survival rates, but for the necessity of a correct planning in clinical conduct, referring the patient to specialized centers, and the necessity of a correct planning of a ruled radical surgery of ovarian cancer (surgical times, surgeon, etc.).

Habitually, diagnosis of adnexal masses is carried out attending to imaging methods, fundamentally ultrasonography, and serum tumor markers. ${ }^{2-5}$

There are different scoring systems to evaluate adnexal masses ultrasonographycally. Ultrasound signs of malignant ovarian tumors include multilocular or multiple cysts, thick or irregular septa or walls, poorly defined borders, papillary projections, solid components and echogenic elements (Table 1).
Solid echogenicity within the tumor is considered potentially malignant, although a high false-positive rate should be considered in the differential diagnosis of malignant masses. Conventional color and pulsed Doppler have been introduced to improve the diagnostic accuracy of gray-scale morphological ultrasonography, but the results are of limited value. ${ }^{6-12}$

In spite of technical advances, survival rates of ovarian cancer have not been improved, for what is necessary to continue investigating in new more sensitive and specific techniques to improve early diagnosis of ovarian tumors.

Three-dimensional ultrasound offers two advances over conventional ultrasound, improved spatial orientation in association with surface rendering and objective quantification of an organs volume and blood flow. ${ }^{13}$

Regarding ovarian tumors, potential advantages of 3D ultrasound would be a more accurate diagnosis of ovarian cancer and the possibility of its detection in early stages. 3D power Doppler angiography (3D-PDA) allows the acquisition of power-Doppler data from an organ or area of tissue as a whole, which may then be displayed providing a means to assess spatial parameters of tissue vascularity (such as a cluster or branching patterns of a vascular network). Through the histogram facility we can investigate tumor neovascularity, calculate vascularization, parameters and assess tumors blood flow in different stages of growth. There are three indices of vascularity to quantificate an organs blood supply applying

Table 1: Ultrasonographic morphologic scoring system by Bajo JM et al (2002)

\begin{tabular}{llll}
\hline Scores & 0 & 1 & 2 \\
\hline Limits & Defined & Partly poorly defined & Poorly defined \\
Borders & Regular & Partly irregular & Mostly irregular \\
Echogenicity & Sonolucent & High echogenicity & Mixed echogenicity \\
Inner walls structure & Smooth and $<3 \mathrm{~mm}$ & Irregular and/or $>3 \mathrm{~mm}$ & Papillarities \\
Septa & No & $<3 \mathrm{~mm}$ & $>3 \mathrm{~mm}$ \\
\hline
\end{tabular}




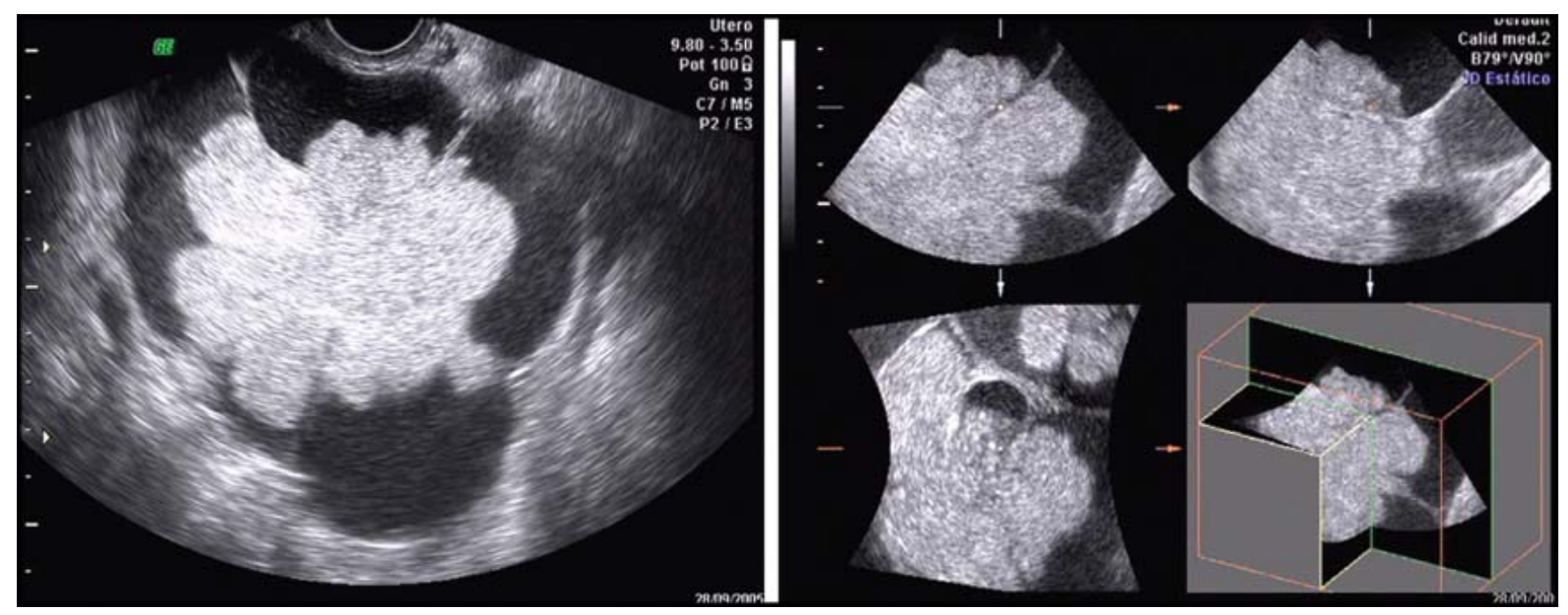

Figs 1 and 2: Three-dimensional ultrasonography may allow a better evaluation of inner walls structure such as a papillarities

3D-PDA: Vascularization index, that reflects the ratio of power Doppler information within the total dataset relative to both color and gray-scale information, the flow index, that represents the mean power Doppler signal intensity, and the vascularization flow index, that is a combination of the two. ${ }^{14-16}$

\section{NEW PERSPECTIVES}

The potential advantages of 3D ultrasound over conventional ultrasonography have been examined in a number of studies to determine their diagnostic value in women with possible gynecological malignancies. These studies vary greatly in their design and patient populations, and offer extensive and possibly contradictory results.

In a pioneer work, Bonilla-Musoles et al tried to determine whether 3D ultrasound may offer advantages over 2D ultrasound as a screening tool for the evaluation of ovarian lessons. They evaluated 76 women with ovarian masses first detected with conventional ultrasound, basing the 3D sonographic criteria for malignancy in the morphologic scoring system for 2D ultrasound proposed by different authors. They stated that observation of papillary projections, characteristics of cystic walls, and the extent of capsular infiltration was superior with 3D ultrasound in comparison to conventional 2D sonography, as was the calculation of ovarian tumor volume. They also indicated that eventually 3D ultrasound imaging will allow diagnosis of ovarian malignancy at an earlier stage (Figs 1 and 2). ${ }^{17}$

Hata et al, in a study of 20 ovarian tumors, reported a higher specificity and accuracy, and a lower false-positive rate for 3D ultrasound compared with 2D sonography, suggesting that 3D ultrasonography might be a better means of differentiating between malignant and benign ovarian tumors. ${ }^{18}$ Both works considered similar morphologic criteria for the diagnosis of ovarian malignancy. Other authors, however, point out that the most important variable in predicting malignancy is the presence or absence of solid elements within the tumor, and find that the use of 3D transvaginal sonography does not significantly improve the $2 \mathrm{D}$ transvaginal sonographic morphologic assessment of complex adnexal masses, though it is useful for reinforcing initial diagnostic impressions. ${ }^{19-21}$

Concerning power Doppler evaluation of complex adnexal masses, Cohen et al published a study over 71 women in which despite all malignancies were correctly identified by both $2 \mathrm{D}$ and 3D imaging, the specificity was significantly improved with the addition of 3D power Doppler. ${ }^{22}$

In an analysis of 43 patients with suspected stage I ovarian cancer, Kurjak et al show that 3D power Doppler and especially the combined use of 3D sonography and power Doppler imaging significantly improve diagnosis accuracy in preoperative sonographic assessment of suspected ovarian lesions. ${ }^{23,24}$

Fishman et al examining the usefulness of sonography in the detection of early-stage of epithelial ovarian cancer find that specificity significantly improved by the addition of 3D Doppler imaging as a secondary test to determine the location of blood flow, but Guerriero et al argued that there is little evidence that 3D Doppler imaging is significantly better than results with 2D gray-scale and color Doppler imaging. Likewise, Testa et al deem that the use of 3D quantification of tumor vascularity yields a diagnostic accuracy, that is, similar to that of subjective evaluation of vascularity. ${ }^{25-27}$

Alcazar et al, however, find that the 3D-PDA index seems to improve the accuracy in evaluation of complex vascular masses compared with conventional power Doppler index. ${ }^{28}$ 


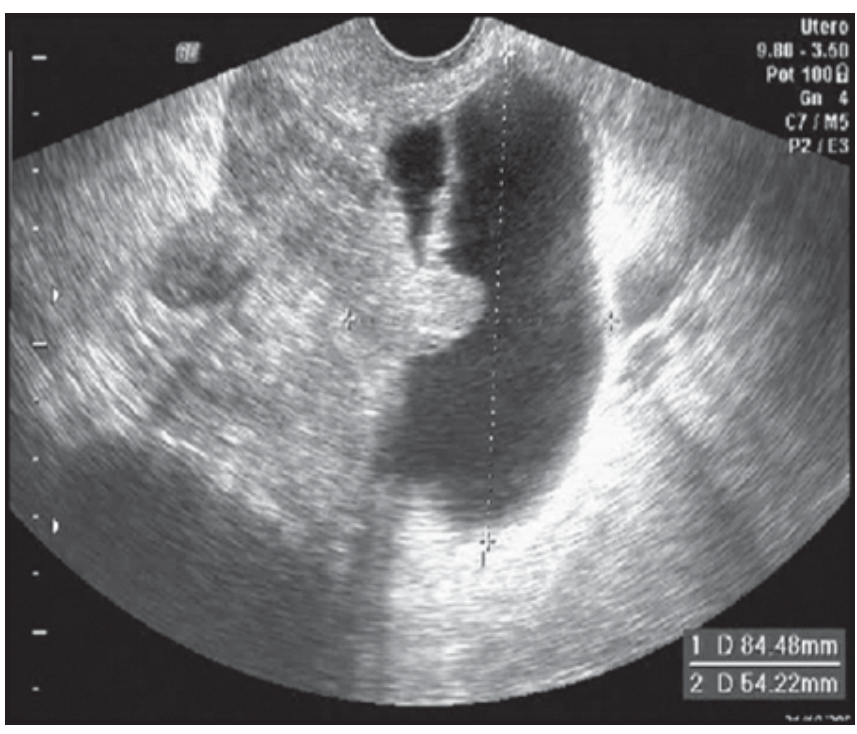

Fig. 3: Complex ovarian tumor. B-mode showed noticeable solid component protruding into the cystic cavity of the tumor. Note thick septa on the basis of the lesion

\section{CONCLUSIONS}

Three-dimensional sonography examination contributes to carry out a volumetric reconstruction of the examined objects and allows an objective quantification of blood flow.

Some studies suggest that it might be a better means in the evaluation of complex adnexal masses. Therefore, further studies are necessary to demonstrate the improved sensitivity and specificity compared to conventional 2D ultrasound (Fig. 3).

\section{REFERENCES}

1. Jemal A, Tiwari RC, Murray T, Ghafoor A, Samuels A, Ward E et al. Cancer statistics 2004. CA Cancer J Clin 2004;54:8-29.

2. Sato S, Yokoyama Y, Sakamoto T, Futagami M, Saito Y. Usefulness of mass screening for ovarian carcinoma using transvaginal ultrasonography. Cancer 2000;89:582-8.

3. Menon U, Jacobs IJ. Ovarian cancer screening in the general population. Ultrasound Obstet Gynecol 2000;15:350-3.

4. Fishman DA, Cohen IS. Is transvaginal ultrasound effective for screening asymptomatic women for the detection of early-stage epithelial ovarian carcinoma?Gynecol Oncol 2000;77:347-9.

5. Paley PJ. Screening for the major malignancies affecting women: current guidelines. Am J Obstet Gynecol 2001;184:1021-30.

6. Sassone MA, Timor-Trisch IE, Artner A, Westhoff C, Waren B. Transvaginal sonographic characterization of ovarian disease: evaluation of a new scoring system to predict ovarian malignancy. Obstet Gynecol 1991;78:70-6.

7. DePriest PD, Shenson D, Fried A, Hunter JE, Andrew SJ, Gallion $\mathrm{HH}$, et al. A morphology index based on sonographic findings in ovarian cancer. Gynecol Oncol 1993;51:7-11.
8. Huertas MA, Uguet C, Romo A, Bajo JM.Ultrasonographic assesment of organic ovarian masses. Ovarian cancer. Ultrasonographic scoring system. Doppler evaluation. In Bajo JM (Ed): Gynecological Ultrasonography. Marbán 2002; pp 141-71.

9. Alcazar JL, Merce LT, Laparte C, Jurado M, López-García G. A new scoring sytem to differentiate benign from malignant adnexal masses. Am J Obstet Gynecol 2003;188:685-92.

10. Tailor A, Jurkovic D, Bourne TH, Collins WP, Campbell S. Sonographic prediction of malignancy in adnexal masses using multivariate logistic regression analysis. Ultrasound Obstet Gynecol 1997;10:41-7.

11. Kurjak A, Predanic M. New scoring system for the prediction of ovarian malignancy based on transvaginal Doppler sonography. J Ultrasound Med 1992;11:631-8.

12. Alcazar JL, Jurado M. Prospective evaluation of a logistic model based on sonographic morphologic and color Doppler findings developed to predict adnexal malignancy. J Ultrasound Med 1999; 18: 837-42.

13. Bega G, Lev-Toaff AS, O'Kane P, Becker E, Kurtz A. Threedimensional ultrasonography in gynecology. Technical aspects and clinical applications. J Ultrasound Med 2003;22:1249-69.

14. Pairleitner H, Steiner H, Hasenoehrl G, Staudach A. Threedimensional power Doppler sonography: imaging and quantifying blood flow and vascularization. Ultrasound Obstet Gynecol 1999;14:139-43.

15. Raine-Fenning NJ, Campbell BK, Clewes JS, Kendall NR, Johnson JR. The reliability of virtual organ computer-aided analysis (VOCAL) for the semiquantification of ovarian, endometrial and subendometrial perfusion. Ultrasound Obstet Gynecol 2003;22:633-9.

16. Fleischer A. Recent advances in the sonographic assessment of vascularity and blood flow in gynaecologic conditions. Obstet Gynecol 2005; 193:294-301.

17. Bonilla-Musoles F, Raga F, Osborne NG. Three-dimensional ultrasound evaluation of ovarian masses.Gynecol Oncol 1995;59:129-35.

18. Hata T, Yanagihara T, Hayashi K, Yamashiro C, Ohnishi Y, Akiyama M, Manabe A, Miyazaki K. Three-dimensional ultrasonographic evaluation of ovarian tumours: a preliminary study. Human Reprod 1999; 14: 3150-1.

19. Alcazar JL, Galan MJ, Garcia-Manero M, Guerriero S. Threedimensional sonographic morphologic assessment in complex adnexal masses: preliminary experience. J Ultrasound Med 2003;22(3):249-54.

20. Timmerman D, Bourne TH, Tailor A, Collins W, Verrelst H, Vandenberghe K, et al. A comparison of methods for preoperative discrimination between malignant and benign masses: the development of a new logistic regression model. Am J Obstet Gynecol 1999;181:57-65.

21. Schelling M, Braun M, Kuhn W, Bogner G, Gruber R, Gnirs J, et al. Combined transvaginal B-mode and color Doppler sonography for differential diagnosis of ovarian tumors: results of a multivariate logistic regression analysis.Gynecol Oncol 2000;77:78-86. 
22. Cohen LS, Escobar PF, Scharm C, Glimco B, Fishman DA. Three-dimensional power Doppler ultrasound improves the diagnostic accuracy for ovarian cancer prediction. Gynecol Oncol 2001;82:40-8.

23. Kurjak A, Kupesic S, sparac V, Kosuta D. Three-dimensional ultrasonography and power Doppler characterization of ovarian lesions. Ultrasound Obstet Gynecol 2000;16:365-71.

24. Kurjack A, Kupesic S, Sparac V, Prka M, Bekavac I. The detection of stage I ovarian cancer by three-dimensional sonography and power Doppler. Gynecol Oncol 2003; 90(2):258-64.

25. Fishman DA, Cohen L, Blank S, Shulman L, Singh D, Bozorgi $\mathrm{K}$, et al. The role of ultrasound evaluation in the detection of early-stage epithelial ovarian cancer. Am J Obstet Gynecol 2005;192:1214-22.
26. Guerriero S, Alcazar JL, Cocía ME, Ajossa S, Scarselli G, Boi $\mathrm{M}$, et al. Complex pelvic mass as a target of evaluation of vessel distribution by color Doppler sonography for the diagnosis of ovarian malignancies: results of a Multicenter European study. J Ultrasound Med 2002;21:1105-11;84(2):352-3.

27. Testa AC, Ajossa S, Ferrandina G, Fruscella E, Ludovisi M, Malaggese M, Scambia G, Melis GB, Guerriero S. Does quantitative análisis of three-dimensional power Doppler angiography have a role in the diagnosis of malignant pelvic solid tumors? A preliminary study. Ultrasound Obstet Gynecol 2005;26:67-72.

28. Alcazar JL, Mercé LT, Garcia-Manero M.Three-dimensional power Doppler vascular sampling: a new method for predicting ovarian cancer in vascularized complex adnexal masses. J Ultrasound Med 2005;24:689-96. 